\title{
Effect of TiC Addition on SnSb-C Composite Anodes for Sodium-ion Batteries
}

\author{
Il Tae Kim, ${ }^{1,2}$ Sang-Ok Kim, ${ }^{1}$ and Arumugam Manthiram ${ }^{1, *}$ \\ ${ }^{1}$ Materials Science and Engineering Program and Texas Materials Institute, The University of \\ Texas at Austin, Austin, TX 78712, USA. ${ }^{2}$ Department of Chemical and Biological Engineering, \\ Gachon University, Seongnam-si, Gyeonggi-do, Republic of Korea
}

\begin{abstract}
Tin-antimony alloy $(\mathrm{SnSb})$ particles dispersed in a conductive matrix comprised of $\mathrm{TiC}$ and carbon have been synthesized by high energy mechanical milling (HEMM) and explored as anodes for sodium-ion batteries. The SnSb-TiC-C samples have been prepared with different TiC and carbon contents in the composite, characterized by X-ray diffraction before and after sodiation and by high-resolution transmission electron microscopy, and compared to $\mathrm{SnSb}-\mathrm{C}$ as a baseline. The SnSb-TiC-C anodes demonstrate better cyclic performance as well as better ratecapability compared to $\mathrm{SnSb}-\mathrm{C}$. In addition, the increase in $\mathrm{TiC}$ content in the composite leads to better electrochemical performance. $\mathrm{SnSb}-\mathrm{TiC}(40 \%)-\mathrm{C}(20 \%)$ and $\mathrm{SnSb}-\mathrm{TiC}(40 \%)-\mathrm{C}(30 \%)$ electrodes exhibit the best electrochemical performance, which could result from both the welldeveloped $\mathrm{SnSb}$ as an electrochemically active nanocrystalline material and the conductive matrix composed of a combination of TiC and carbon. Additionally, the use of FEC electrolyte additive results in much better electrochemical performance even at high-rate current density when combined with this material due to the formation of a stable and thin SEI layer.
\end{abstract}

Keywords: sodium-ion batteries, tin-antimony alloy anodes, titanium carbide, electrolyte additives

* Corresponding author. Tel: +1-512-471-1791; fax: +1-512-471-7681. E-mail address: manth@austin.utexas.edu (A. Manthiram) 


\section{Introduction}

Wide attention has been recently paid toward sodium-ion batteries (SIBs) as an alternative to lithium-ion batteries (LIBs) due to its low cost, high abundance, and reduction/oxidation potential only $\sim 0.3 \mathrm{~V}$ above that of lithium; particularly, the attention has been towards largescale energy storage applications [1-5]. Several cathode materials have been examined for SIBs [1, 6-9]. In contrast, anodes for SIBs encounter more challenges because of the very low Nastorage capacity of commercial graphite [10]. As a result, hard carbons have been explored as anode materials to realize viable carbon anodes for SIBs [11-13]. In addition, various carbon materials have also been investigated, particularly to increase sodium-ion insertion into carbonbased materials $[14,15]$. However, the reversibility for carbonaceous materials still remains a major issue [11]. Furthermore, the carbon-based anode materials are facing great challenges in association with sodium plating, resulting from their operating voltage close to that of $\mathrm{Na} / \mathrm{Na}^{+}$. As a result, alternate ways to cope with these challenges arising from utilizing carbonaceous anode materials have been proposed, in which (inter)metallic alloy systems are included [16-21].

Developing (inter)metallic alloy systems as an anode has been extensively considered as a potential strategy for sodium-ion batteries. In these systems, $\mathrm{Na}$ ions are capable of reacting with various (inter)metallic elements, such as tin ( $\mathrm{Sn})$, antimony (Sb), and germanium (Ge), and forming an alloy during sodiation $[16,17]$. Sodium-alloys (Na-alloys), however, suffer from enormous volume changes upon uptake or removal of $\mathrm{Na}\left(\right.$ e.g., $\sim 424 \%$ for $\mathrm{Na}_{15} \mathrm{Sn}_{4}$, and $\sim 390 \%$ for $\mathrm{Na}_{3} \mathrm{Sb}$ ), which are even larger than those of the corresponding lithium-alloys (Li-alloys), posing greater limitations for the realization of durable anodes. For example, Ellis et al. [22] developed a sputtered Sn electrode and observed an initial discharge capacity of $\sim 850 \mathrm{mAh} \mathrm{g}^{-1}$. However, this electrode showed rapid cycling-induced capacity degradation to near zero. 
Yamamoto et al. [23] reported a Sn thin film as an anode for SIBs, which exhibited a charge capacity of $729 \mathrm{mAh} \mathrm{g}^{-1}$ in the first cycle; after that, it exhibited a rapid capacity fade after 15 cycles. In addition, Baggetto et al. [24] developed a AlSb thin film electrode prepared via magnetron sputtering for SIBs and LIBs. In the case of SIBs, however, the capacity retention and the kinetics with $\mathrm{Na}$ were not satisfactory. In this regard, the exploration of a composite system in which the electrochemically active (inter)metallic components are well-dispersed in a conductive matrix could be an attractive way to realize high-performance sodium-ion batteries.

In the present work, we report the synthesis, electrochemical performance, and sodiumion storage mechanisms of tin-antimony alloy anodes, $\mathrm{SnSb}-\mathrm{TiC}-\mathrm{C}$, for sodium-ion cells. The SnSb-C electrode exhibits gradual capacity fading upon cycling. TiC has high electrical conductivity and is denser than carbon, so the combination of $\mathrm{TiC}$ with carbon can build a good conductive matrix with high tap density that can lead to lower impedance and better electrochemical performance. Furthermore, the $\mathrm{SnSb}$ nanocrystallites dispersed in the TiC-C conductive matrix could overcome the difficulties accompanying alloy anodes since the TiC-C matrix acts as a buffer to absorb the large volume change during the alloying reaction as well as maintains the nanoparticle separation during cycling.

\section{Experimental}

\subsection{Synthesis of SnSb-TiC-C composites}

For the preparation of SnSb-TiC-C nanocomposite, precursor powders of Sb:Ti and Sn:Ti with molar ratios of 3:1, 3:2, and 7:13 were prepared by mixing the metallic powders of $\mathrm{Sb}$ (99.9\%, Alfa Aesar) or Sn (99.9\%, Aldrich) and Ti (99.99\%, Alfa Aesar) and heat-treating at 600

${ }^{\circ} \mathrm{C}$ in an Ar atmosphere for $12 \mathrm{~h}$. After that, required amount of Sb-Ti and Sn-Ti powder samples 
were mixed with stoichiometric amount of acetylene black to form the TiC phase and with 20 wt. \% or 30 wt. \% excess acetylene black, and subjected to HEMM. For the preparation of SnSb$\mathrm{C}$, a $1: 1$ molar ratio of $\mathrm{Sn}$ and $\mathrm{Sb}$ as well as $20 \mathrm{wt}$ \% acetylene black were mixed, followed by HEMM. The SnSb-TiC-C sample with 30 wt. \% carbon content in the composite is marked as $\mathrm{C}(30 \%)$. Otherwise, the carbon content in the composites is $20 \mathrm{wt}$ \%. The powder mixtures were placed in hardened steel vials $\left(80 \mathrm{~cm}^{3}\right.$ capacity) with steel balls of diameter $1 / 2$ and $1 / 4$ in. at a ball : powder mass ratio of $20: 1$. All HEMM process was carried out at a speed of $500 \mathrm{rpm}$ under Argon atmosphere with a Fritsch Pulverisette 6 planetary mill. The milling times for SnSb$\mathrm{C}$ and $\mathrm{SnSb}$-TiC-C were both $40 \mathrm{~h}$. The TiC content was controlled by changing the molar ratio of $\mathrm{Sn}: \mathrm{Ti}$ and $\mathrm{Sb}: \mathrm{Ti}$ and introducing required amount of stoichiometric carbon to give 25, 40, and 65 wt. $\%$ TiC in the composite.

\subsection{Materials Characterization}

The as-prepared samples were examined with a Rigaku RINT 2000 diffractometer and $\mathrm{Cu} \mathrm{K} \alpha$ radiation in the range of $10-70^{\circ}$ with a scan rate of $0.03^{\circ} \mathrm{s}^{-1}$ for structural characterization. The ex situ XRD measurements were conducted with the tested electrochemical cells at different states of charge. The electrodes were disassembled in an Ar-filled glove box and rinsed with anhydrous dimethyl carbonate to remove the residual salts. The nanostructure and composition of the powder samples were characterized with a JEOL 2010F transmission electron microscope.

\subsection{Electrochemical Measurements}

For the measurements of electrochemical performance, electrodes were prepared on $\mathrm{Cu}$ foils with slurries comprised of 70 wt. \% active material, 15 wt. \% Super P, 15 wt. \% PVDF, and $\mathrm{N}$-methylpyrrolidone (NMP). The electrodes were dried at $60{ }^{\circ} \mathrm{C}$ for $3 \mathrm{~h}$ in an oven and at 120 
${ }^{\circ} \mathrm{C}$ overnight in a vacuum oven. The cells were assembled with sodium as the counter electrode, a sample electrode as the working electrode, $1 \mathrm{M} \mathrm{NaClO}_{4}$ in a mixture of ethylene carbonate (EC)/propylene carbonate (PC) (1:1 by volume) as the electrolyte, and a glass separator (APFA from Millipore). For a comparison, 2 vol. \% of fluoroethylene carbonate (FEC) was introduced as an electrolyte additive. The test electrodes had an active material $(\mathrm{SnSb})$ content of $1-1.5$ $\mathrm{mg}$, but the capacity values were calculated based on the total weight of the composite $(\mathrm{SnSb}+$ $\mathrm{TiC}+\mathrm{C})$. The galvanostatic charge/discharge experiments were carried out at a constant current density of $100 \mathrm{~mA} \mathrm{~g}^{-1}$ at $0.0-1.5 \mathrm{~V} \mathrm{vs.} \mathrm{Na} / \mathrm{Na}^{+}$. Electrochemical impedance spectroscopy (EIS) analysis was conducted with a Solartron SI 1260 instrument with an applied amplitude of $10 \mathrm{mV}$ in the range of $100 \mathrm{kHz}$ to $0.1 \mathrm{~Hz}$ after various cycles at $1.5 \mathrm{~V}$ vs. $\mathrm{Na} / \mathrm{Na}^{+}$.

\section{Results and Discussion}

Fig. 1 shows the XRD pattern of the as-prepared $\mathrm{SnSb}-\mathrm{C}$ and $\mathrm{SnSb}-\mathrm{TiC}-\mathrm{C}$ composites. In the case of the $\mathrm{SnSb}-\mathrm{C}$ composite, the pattern shows pure $\mathrm{SnSb}$ crystalline phase, with no pure $\mathrm{Sb}$ and $\mathrm{Sn}$ peaks, and amorphous carbon [16]. In the case of SnSb-TiC-C, additional TiC peaks at around $36.3^{\circ}(111)$ and $60.8^{\circ}(220)$ are observed [25]. The peak intensity increases with increasing TiC wt. \% (from 25\% to 40\%) as seen in Fig. 1. The SnSb-TiC-C composites also display only pure $\mathrm{SnSb}$ and $\mathrm{TiC}$ phases with no $\mathrm{Sn}, \mathrm{Sb}$, and Ti phases, illustrating that the reactions to form $\mathrm{SnSb}$ and $\mathrm{TiC}$ nanocrystallites are completed during HEMM.

The morphology results are given in Fig. 2. The $\mathrm{SnSb}$ and $\mathrm{TiC}$ nanoparticles are well dispersed in the carbon matrix (Fig. 2a). The high resolution transmission electron microscopy (HRTEM) images illustrate interplanar spacings of 0.31 and $0.25 \mathrm{~nm}$, respectively, corresponding to the (101) planes of SnSb and (111) planes of TiC. 
Fig. 3 compares the initial discharge and charge voltage profiles of SnSb-C and SnSbTiC-C electrodes at a current rate of $100 \mathrm{~mA} \mathrm{~g}^{-1}$. The SnSb-C electrode exhibits the highest charge capacity of $475 \mathrm{mAh} \mathrm{g}^{-1}$. When increasing the TiC content in the composite, which is an electrochemically inactive component (see Fig. S1 in supporting information), the charge capacity decreases due to the decrease in the weight percent of the electrochemically active component $(\mathrm{SnSb})$ in the composite; for instance, $\mathrm{SnSb}-\mathrm{TiC}(25 \%)-\mathrm{C}$ has an initial charge capacity of $388 \mathrm{mAh} \mathrm{g}^{-1}$ while $\mathrm{SnSb}-\mathrm{TiC}(40 \%)-\mathrm{C}$ has $325 \mathrm{mAh} \mathrm{g}^{-1}$. Nevertheless, the addition of the $\mathrm{TiC}$ into $\mathrm{SnSb}-\mathrm{C}$ leads to better electrochemical performance due to its high conductivity, resulting in small increase in impedance, and well-dispersed characteristics as a matrix component (discussed later). In addition, when increasing the carbon content while maintaining the same $\mathrm{TiC}$ content in the composite, the initial charge capacity decreases as well. For example, SnSb-TiC (40\%)-C(20\%) delivers a higher initial charge capacity (325 $\left.\mathrm{mAh} \mathrm{g}^{-1}\right)$ than SnSb$\mathrm{TiC}(40 \%)-\mathrm{C}(30 \%)\left(305 \mathrm{mAh} \mathrm{g}^{-1}\right)$. Specifically, the capacity values of carbon in sodium-ion cells differ depending on the experimental conditions including synthesis process, voltage range, electrolyte used, type of carbon, etc. Ponrouch et al.[13] reported that the capacity range of the as-prepared carbon varies $\sim 200 \mathrm{mAh} \mathrm{g}^{-1}$ to $\sim 300 \mathrm{mAh} \mathrm{g}^{-1}$ based on the specific surface area and degree of graphitization. We found the initial charge capacity of the acetylene black after milling for $40 \mathrm{~h}$ to be $\sim 220 \mathrm{mAh} \mathrm{g}^{-1}$ (see Fig. S2 in supporting information). However, the capacity contribution of carbon could vary in the range of $200-300 \mathrm{mAh} \mathrm{g}^{-1}$ when the carbon matrix is developed with active materials (e.g., SnSb) and other matrices (e.g., TiC). The initial capacities of the $\mathrm{SnSb}-\mathrm{TiC}(40 \%)-\mathrm{C}(30 \%)$ electrodes with three different cells were found to be in the range of $300 \mathrm{mAh} \mathrm{g}^{-1}$ to $307 \mathrm{mAh} \mathrm{g}^{-1}$. Taking the initial charge capacity of SnSb-TiC(40\%)-C(30\%) as $303 \mathrm{mAh} \mathrm{g}^{-1}$ and assuming an initial capacity contribution of $\sim 260 \mathrm{mAh} \mathrm{g}^{-1}$ by carbon, the 
calculated capacity value of $\mathrm{SnSb}$ is $\sim 750 \mathrm{mAh} \mathrm{g}^{-1}\left((750 \times 0.3)+(260 \times 0.3)=303 \mathrm{mAh} \mathrm{g}^{-1}\right)$.

The sodiation/desodiation reactions can be evaluated from the differential capacity plots as shown in Fig. 4. During the first discharge (sodiation) scan, broad irreversible peaks around 0.8 and $0.5 \mathrm{~V}$ are observed. They are ascribed to the irreversible decomposition of the electrolyte and formation of solid-electrolyte interphase (SEI) layer on the surface of the composite. During the second discharge scan, four peaks are observed at $0.57,0.37,0.27$, and $0.00 \mathrm{~V}$. In the reverse charge (desodiation) scan, four peaks centered at $0.11,0.20,0.55$, and $0.90 \mathrm{~V}$ are detected as well. It is noted that the electrochemical mechanism of $\mathrm{SnSb}$ with $\mathrm{Na}$ is not the simple addition of those of $\mathrm{Sn}$ and $\mathrm{Sb}$ with $\mathrm{Na}$ [26]. The reaction of $\mathrm{SnSb}$ with $\mathrm{Na}$ occurs at different potentials compared to those observed for Sn-C and Sb-C as shown in Fig. 4b and c. Based on the differential capacity plots of Sn-C and Sb-C electrodes, the two peaks at $\sim 0.00$ and $0.27 \mathrm{~V}$ can be assigned to the sodium-ion reaction with acetylene black carbon and sodium-tin (Na-Sn). The peaks at $0.37 \mathrm{~V}$ mainly corresponds to the sodium-antimony (Na-Sb) alloying reaction along with the Na-Sn alloying reaction. Furthermore, the broad peak centered at $0.57 \mathrm{~V}$ is related to the $\mathrm{Na}-\mathrm{Sb}$ alloying reaction. In the charge scan, the peaks at 0.11 and $0.20 \mathrm{~V}$ are ascribed to the sodium-ion extraction out of acetylene black carbon and $\mathrm{Na}-\mathrm{Sn}$. In addition, the peak centered at $0.55 \mathrm{~V}$ with a broad shoulder up to $0.76 \mathrm{~V}$ can be ascribed to the overlapping of the Na-Sn and $\mathrm{Na}-\mathrm{Sb}$ dealloying reactions, while the peak at $0.90 \mathrm{~V}$ is due to the $\mathrm{Na}-\mathrm{Sb}$ dealloying reaction. This sodiation/desodiation mechanism of SnSb-TiC-C electrodes was further examined by ex situ XRD as illustrated in Fig. 5. When discharged to $0 \mathrm{~V}$ vs. $\mathrm{Na} / \mathrm{Na}^{+}$(full sodiation), additional peaks can be observed at around $31.9^{\circ}$ and $38.6^{\circ}$, which correspond to the formation of, respectively, $\mathrm{Na}_{15} \mathrm{Sn}_{4}$ and $\mathrm{Na}_{3} \mathrm{Sb}$ alloys, while the $\mathrm{SnSb}$ peaks disappear. In addition, there are still remaining peaks at $36.2^{\circ}$ and $42.0^{\circ}$ at $0 \mathrm{~V}$, which are related to the TiC crystalline peaks, 
illustrating that $\mathrm{TiC}$ is persistent throughout the sodiation. When fully desodiated (1.5 V vs. $\mathrm{Na} / \mathrm{Na}^{+}$), the phases of $\mathrm{Na}_{15} \mathrm{Sn}_{4}$ and $\mathrm{Na}_{3} \mathrm{Sb}$ disappear, while crystalline $\mathrm{SnSb}$ peaks appear again along with the unchanged TiC peaks, illustrating that crystalline $\mathrm{SnSb}$ phase is reversible during cycling.

Fig. 6 shows the cyclability of SnSb-C and SnSb-TiC-C electrodes at a current rate of $100 \mathrm{~mA} \mathrm{~g}^{-1}$. The solid symbols represent the discharge capacity of the as-prepared electrode materials while the open symbols correspond to their charge capacity. The electrodes with FEC additive exhibit lower capacities than those without FEC additive. The addition of FEC leads to a decomposition at $\sim 0.8 \mathrm{~V}$ in the first discharge and leads to the formation of a stable SEI layer, which results in a slightly lower initial discharge capacity [27]. In addition, there is no significant difference in the initial Coulombic efficiency before and after FEC addition. Therefore, the electrode with FEC additive exhibits lower charge capacity than that without FEC additive (see Fig. S3 in supporting information). In the case of $\mathrm{SnSb}-\mathrm{C}$ electrode, gradual capacity fade occurs during cycling. By increasing the TiC content in the composite, the cyclability of SnSb-TiC-C electrodes becomes better than that of the $\mathrm{SnSb}-\mathrm{C}$ electrode. In the case of $\mathrm{SnSb}-\mathrm{TiC}(65 \%)-\mathrm{C}$ composite anode, stable cyclability is seen; however, due to the large amount of $\mathrm{TiC}$ in the composite, it only exhibits a charge capacity of $100 \mathrm{mAh} \mathrm{g}^{-1}$. The $\mathrm{SnSb}-\mathrm{TiC}(25 \%)-\mathrm{C}$ composite anode delivers a charge capacity of $150 \mathrm{mAh} \mathrm{g}^{-1}$ at 30 cycles, which corresponds to a capacity retention of $40 \%$, while the $\mathrm{SnSb}-\mathrm{C}$ exhibits a capacity retention of only $22 \%$ at 30 cycles. When the TiC content in the composite is increased to $40 \mathrm{wt} \%$, the $\mathrm{SnSb}-\mathrm{TiC}(40 \%)-\mathrm{C}$ electrode shows a charge capacity of $210 \mathrm{mAh} \mathrm{g}^{-1}$ at 30 cycles corresponding to a capacity retention of $65 \%$. Furthermore, when the carbon content increases from $20 \%$ to $30 \%$ with the same TiC content of $40 \%$, the $\mathrm{SnSb}-\mathrm{TiC}(40 \%)-\mathrm{C}(30 \%)$ electrode delivers a capacity of $215 \mathrm{mAh} \mathrm{g}^{-1}$, 
which represents a capacity retention of $71 \%$ at 30 cycles. This superior performance could be attributed to the incorporation of a hybrid conductive matrix consisting of $\mathrm{TiC}$ and carbon, resulting in low impedance. In addition, it is noted that when 2 vol. \% of FEC additive is introduced into the electrolyte, the $\mathrm{SnSb}-\mathrm{TiC}-\mathrm{C}$ electrodes exhibit longer cyclic life as illustrated in Fig. 6b. In contrast, the SnSb-C anode does not exhibit stable cyclability even when adding the FEC additive into the electrolyte. The SnSb-TiC(25\%)-C electrode cycled with FEC shows better cyclability than the SnSb-TiC(25\%)-C electrode without FEC additive, but it still shows gradual decay in capacity. On the other hand, when cycled with FEC additive, the SnSb$\mathrm{TiC}(40 \%)$-C electrode shows a capacity retention of $55 \%$ at 70 cycles, while the $\mathrm{SnSb}$ $\mathrm{TiC}(40 \%)-\mathrm{C}(30 \%)$ electrode demonstrates a capacity retention of $73 \%$ at 70 cycles. This result could be due to a thin and stable SEI layer formation on the electrode surface during prolonged cycling $[27,28]$.

The cyclic performance was further investigated with electrochemical impedance spectroscopic plots. Each plot consists of two semicircles and one slope. The first semicircle in the high-frequency region is related to the interfacial layer of the electrodes, while the second semicircle in the medium-frequency region corresponds to the charge-transfer reaction between the active-anode mass and sodium at the electrode surface. The slope in the low-frequency region is attributed to the sodium-ion diffusion through the bulk material. The intercept of the first semicircle with the real axis is related to the ohmic resistance, and the diameter of the second semicircle represents the charge-transfer resistance. When observing the EIS spectra at various cycle numbers, the $\mathrm{SnSb}-\mathrm{C}$ electrode exhibits great increase in impedance even at low cycle numbers as seen in Fig. 7a, illustrating a significant increase in SEI film resistance $\left(R_{s}\right)$ and charge transfer resistance $\left(R_{c t}\right)$ during cycling. In contrast, the $\mathrm{SnSb}$-TiC $(40 \%)$-C electrodes 
show smaller increase in impedance as illustrated in Fig. $7 b$ and $c$ than the SnSb-C electrode. The EIS data are summarized in Table 1 . In the case of $\mathrm{SnSb}-\mathrm{C}$ electrode, the \% increases in $\mathrm{R}_{\mathrm{s}}$ and $\mathrm{R}_{\mathrm{ct}}$ between the initial and the $40^{\text {th }}$ cycle are, respectively, $429 \%$ and $1382 \%$, revealing a significant increase in impedance. On the other hand, the $\mathrm{SnSb}-\mathrm{TiC}(40 \%)-\mathrm{C}$ and $\mathrm{SnSb}-$ $\mathrm{TiC}(40 \%)-\mathrm{C}(30 \%)$ electrodes exhibit much smaller increase in impedance between the initial and the $40^{\text {th }}$ cycle as shown in Table 1 . Therefore, the electrodes with $\mathrm{TiC}$ as a matrix exhibit lower impedance as discussed, and it is confirmed that $\mathrm{SnSb}-\mathrm{TiC}-\mathrm{C}$ electrodes show better electrochemical performance than SnSb-C.

When looking at the rate capability of the as-prepared electrodes as shown in Fig.8, the $\mathrm{SnSb}-\mathrm{TiC}-\mathrm{C}$ electrodes display better rate capability than $\mathrm{SnSb}-\mathrm{C}$. The electrodes demonstrating better cyclic performance exhibit better rate performance. The $\mathrm{SnSb}-\mathrm{C}$ electrode shows poor rate capability similar to the inferior cycling performance seen in Fig. 6. On the other hand, the electrodes with $\mathrm{TiC}$ exhibit better rate capability. The $\mathrm{SnSb}-\mathrm{TiC}(25 \%)$-C electrode delivers a capacity of $200 \mathrm{mAh} \mathrm{g}^{-1}$ at a current rate of 3,000 $\mathrm{mA} \mathrm{g}^{-1}$, demonstrating a capacity retention of $50 \%$ when normalized by the capacity at $100 \mathrm{~mA} \mathrm{~g}^{-1}$. The $\mathrm{SnSb}-\mathrm{TiC}(40 \%)-\mathrm{C}$ electrodes demonstrate much better rate capabilities of $220 \mathrm{mAh} \mathrm{g}^{-1}$ for $\mathrm{SnSb}-\mathrm{TiC}(40 \%)-\mathrm{C}$ and $230 \mathrm{mAh} \mathrm{g}^{-1}$ for $\mathrm{SnSb}-\mathrm{TiC}(40 \%)-\mathrm{C}(30 \%)$ at 3,000 $\mathrm{mA} \mathrm{g}^{-1}$, which correspond to a capacity retention of, respectively, $61 \%$ and $78 \%$, as illustrated in Fig. 8c. Furthermore, when introducing 2 vol. $\%$ of FEC additive into the electrolyte, the as-prepared electrodes exhibit higher-rate capability as shown in Fig. 8b and c. The capacity retentions of SnSb-TiC(25\%)-C, SnSb-TiC(40\%)-C, and $\mathrm{SnSb}-\mathrm{TiC}(40 \%)-\mathrm{C}(30 \%)$ at $3,000 \mathrm{~mA} \mathrm{~g}^{-1}$ are $54 \%, 72 \%$, and $88 \%$, respectively, when cycled with FEC additive. This high-rate capability could be due to the formation of more stable and thin SEI layer when adding 2 vol. \% of FEC additive together with the smaller charge-transfer 
resistance, better dispersion of the particles upon cycling [28, 29].

\section{Conclusions}

SnSb-TiC-C nanocomposites with different TiC contents synthesized via HEMM have been examined as anode materials for sodium-ion cells. The introduction of $\mathrm{TiC}$ into the composite leads to better cyclability as well as high-rate performance compared to the SnSb-C composite without TiC. Specifically, the SnSb-TiC(40\%)-C electrode exhibits good cyclability

with $210 \mathrm{mAh} \mathrm{g}^{-1}$ at $100 \mathrm{~mA} \mathrm{~g}^{-1}$ after 30 cycles and a normalized capacity retention of $\sim 61 \%$ on increasing the current rate to $3,000 \mathrm{~mA} \mathrm{~g}^{-1}$. Furthermore, when increasing the carbon content to $30 \%$ with the same $\mathrm{TiC}$ content of $40 \%$, the $\mathrm{SnSb}-\mathrm{TiC}(40 \%)-\mathrm{C}(30 \%)$ electrode demonstrates better cyclic performance and higher rate capability with a capacity retention of $78 \%$ at 3,000 $\mathrm{mA} \mathrm{g}^{-1}$. When 2 vol. \% FEC additive is introduced into the electrolyte, the $\mathrm{SnSb}-\mathrm{TiC}(40 \%)-\mathrm{C}$ (30\%) electrode exhibits longer cyclic life with a capacity retention of $73 \%$ at 70 cycles and superior rate capability with $\sim 88 \%$ retention at $3,000 \mathrm{~mA} \mathrm{~g}^{-1}$. This enhanced electrochemical performance could be mainly pertinent to thin and stable SEI layer formation along with smaller charge-transfer resistance and better dispersion of the electrochemically active material in the conductive matrix of $\mathrm{TiC}$ and carbon. Nevertheless, the electrodes with $\mathrm{TiC}$ addition still suffer from capacity decay, which might result from the large volume change that the TiC-C matrix cannot endure. Our future work will focus on developing better matrix combinations for accommodating the volume changes more efficiently with sodium-ion cells.

\section{Acknowledgements}

This work was supported by the U.S. Department of Energy, Office of Basic Energy Sciences, Division of Materials Sciences and Engineering under award number DE-SC0005397. 


\section{References}

[1] B.L. Ellis, L.F. Nazar, Curr. Opin. Solid State Mater. 16 (2012) 168-177.

[2] N. Yabuuchi, M. Kajiyama, J. Iwatate, H. Nishikawa, S. Hitomi, R. Okuyama, R. Usui, Y. Yamada, S. Komaba, Nat. Mater. 11 (2012) 512-517.

[3] X.C. Lu, G.G. Xia, J.P. Lemmon, Z.G. Yang, J. Power Sources 195 (2010) 2431-2442.

[4] S.P. Ong, V.L. Chevrier, G. Hautier, A. Jain, C. Moore, S. Kim, X. Ma, G. Ceder, Energy Environ. Sci. 4 (2011) 3680-3688.

[5] S. Komaba, W. Murata, T. Ishikawa, N. Yabuuchi, T. Ozeki, T. Nakayama, A. Ogata, K. Gotoh, K. Fujiwara, Adv. Funct. Mater. 21 (2011) 3859-3867.

[6] K.-H. Ha, S.H. Woo, D. Mok, N.-S. Choi, Y. Park, S.M. Oh, Y. Kim, J. Kim, J. Lee, L.F. Nazar, K.T. Lee, Adv. Energy Mater. 3 (2013) 770-776.

[7] R. Berthelot, D. Carlier, C. Delmas, Nat. Mater. 10 (2011) 74-U73.

[8] Y. Lu, L. Wang, J. Cheng, J.B. Goodenough, Chem. Commun. 48 (2012) 6544-6546.

[9] R. Tripathi, G.R. Gardiner, M.S. Islam, L.F. Nazar, Chem. Mater. 23 (2011) 2278-2284.

[10] A.G. Metrot, D; Billaud, D; Herold, A, Syntheitc Met. 1 (1980) 363-369.

[11] R. Alcantara, J.M. Jimenez-Mateos, P. Lavela, J.L. Tirado, Electrochem. Commun. 3 (2001) 639-642.

[12] X. Xia, M.N. Obrovac, J.R. Dahn, Electrochem. Solid-State Lett. 14 (2011) A130-A133.

[13] A. Ponrouch, A.R. Goni, M. Rosa Palacin, Electrochem. Commun. 27 (2013) 85-88.

[14] Y. Cao, L. Xiao, M.L. Sushko, W. Wang, B. Schwenzer, J. Xiao, Z. Nie, L.V. Saraf, Z. Yang, J. Liu, Nano Lett. 12 (2012) 3783-3787.

[15] D.A. Stevens, J.R. Dahn, J. Electrochem. Soc. 147 (2000) 1271-1273.

[16] L. Xiao, Y. Cao, J. Xiao, W. Wang, L. Kovarik, Z. Nie, J. Liu, Chem. Commun. 48 (2012) 
$3321-3323$.

[17] L. Baggetto, J.K. Keum, J.F. Browning, G.M. Veith, Electrochem. Commun. 34 (2013) 4144.

[18] X. Zhou, Z. Dai, J. Bao, Y.-G. Guo, J Mater. Chem. A 1 (2013) 13727-13731.

[19] L. Baggetto, P. Ganesh, C.-N. Sun, R.A. Meisner, T.A. Zawodzinski, G.M. Veith, J Mater. Chem. A 1 (2013) 7985-7994.

[20] L. Wu, P. Pei, R. Mao, F. Wu, Y. Wu, J. Qian, Y. Cao, X. Ai, H. Yang, Electrochim. Acta 87 (2013) 41-45.

[21] L.H. Wu, Xiaohong; Qian, Jiangfeng; Pei, Feng; Wu, Fayuan; Mao, Rongjun; Ai, Xinping; Yang, Hanxi; Cao, Yuliang, Energy Environ. Sci. 7 (2014) 323-328.

[22] L.D. Ellis, P.P. Ferguson, M.N. Obrovac, J. Electrochem. Soc. 160 (2013) A869-A872.

[23] T. Yamamoto, T. Nohira, R. Hagiwara, A. Fukunaga, S. Sakai, K. Nitta, S. Inazawa, J Power Sources 217 (2012) 479-484.

[24] L. Baggetto, M. Marszewski, J. Gorka, M. Jaroniec, G.M. Veith, J Power Sources 243 (2013) 699-705.

[25] X.Z. Zhu, Kunyu; Cheng, Baochang; Lin, Qiushi; Zhang, Xiuqin; Chen, Tieli; Su, Yunsheng, Mater. Sci. Eng. C 16 (2001) 103-105.

[26] A. Darwiche, M.T. Sougrati, B. Fraisse, L. Stievano, L. Monconduit, Electrochem. Commun. 32 (2013) 18-21.

[27] S. Komaba, T. Ishikawa, N. Yabuuchi, W. Murata, A. Ito, Y. Ohsawa, Acs Appl. Mater. Interfaces 3 (2011) 4165-4168.

[28] L. Liao, X. Cheng, Y. Ma, P. Zuo, W. Fang, G. Yin, Y. Gao, Electrochim. Acta 87 (2013) $466-472$. 
[29] S. Park, J.H. Ryu, S.M. Oh, J. Electrochem. Soc. 158 (2011) A498-A503. 
Table 1. Comparison of the SEI film resistance $\left(R_{S}\right)$ and charge transfer resistance $\left(R_{c t}\right)$ of SnSb$\mathrm{C}, \mathrm{SnSb}-\mathrm{TiC}(40 \%)-\mathrm{C}$, and $\mathrm{SnSb}-\mathrm{TiC}(40 \%)-\mathrm{C}(30 \%)$ electrodes at $1^{\text {st }}$ and $40^{\text {th }}$ cycle

\begin{tabular}{ccccccc}
\hline & $\begin{array}{c}\mathrm{R}_{\mathrm{s}}{ }^{1 \text { st }} \\
(\mathrm{ohm} \mathrm{g})\end{array}$ & $\begin{array}{c}\mathrm{R}_{\mathrm{s}}{ }^{40 \text { th }} \\
(\mathrm{ohm} \mathrm{g})\end{array}$ & $\begin{array}{c}\text { Increase } \\
(\%)\end{array}$ & $\begin{array}{c}\mathrm{R}_{\mathrm{ct}}{ }^{1 \text { st }} \\
(\mathrm{ohm} \mathrm{g})\end{array}$ & $\begin{array}{c}\mathrm{R}_{\mathrm{ct}}{ }^{40 \text { th }} \\
(\mathrm{ohm} \mathrm{g})\end{array}$ & $\begin{array}{c}\text { Increase } \\
(\%)\end{array}$ \\
\hline SnSb-C & 0.056 & 0.296 & 429 & 0.984 & 14.58 & 1382 \\
SnSb-TiC(40\%)-C & 0.081 & 0.173 & 114 & 1.203 & 3.152 & 162 \\
$\mathrm{SnSb-TiC}(40 \%)-\mathrm{C}(30 \%)$ & 0.085 & 0.144 & 69 & 0.531 & 1.083 & 104 \\
\hline
\end{tabular}




\section{Figure captions}

Figure 1. XRD patterns of SnSb-C, SnSb-TiC(25\%)-C, and SnSb-TiC(40\%)-C composites, with the reference peaks of $\mathrm{SnSb}$ and $\mathrm{TiC}$ indicated.

Figure 2. (a) TEM image of SnSb-TiC-C nanocomposite. (b) High-resolution TEM image of SnSb-TiC-C nanocomposite, with the inset showing the electron diffraction pattern over the selected region.

Figure 3. Initial voltage profiles of $\mathrm{SnSb}-\mathrm{C}$ and $\mathrm{SnSb}-\mathrm{TiC}-\mathrm{C}$ electrodes with different $\mathrm{TiC}$ and carbon contents at $100 \mathrm{~mA} \mathrm{~g}^{-1}$.

Figure 4. Differential capacity plots of (a) SnSb-TiC(40\%)-C, (b) Sn-C, and (c) Sb-C electrodes between $0.0 \mathrm{~V}$ and $1.5 \mathrm{~V}$.

Figure 5. Ex-situ XRD patterns of SnSb-TiC-C composite anodes before cycling, after full sodiation $(0 \mathrm{~V})$, and after full desodiation $(1.5 \mathrm{~V})$. The * represents the formation of $\mathrm{Na}_{15} \mathrm{Sn}_{4}$ phase and the \# corresponds to the formation of $\mathrm{Na}_{3} \mathrm{Sb}$ phase.

Figure 6. Comparison of the cyclic performances of SnSb-C and SnSb-TiC-C with different TiC and carbon contents (a) without and (b) with 2 vol. $\%$ of FEC additive at $100 \mathrm{~mA} \mathrm{~g}^{-1}$. 
Figure 7. Electrochemical impedance spectra (EIS) of (a) SnSb-C, (b) SnSb-TiC(40\%)-C, and (c) $\mathrm{SnSb}-\mathrm{TiC}(40 \%)-\mathrm{C}(30 \%)$ electrodes.

Figure 8. Rate cyclic performance of $\mathrm{SnSb}-\mathrm{C}$ and $\mathrm{SnSb}-\mathrm{TiC}-\mathrm{C}$ with different $\mathrm{TiC}$ and carbon contents (a) without and (b) with 2 vol. \% of FEC additive at various current rates. (c) Normalized \% charge capacity retention values of $\mathrm{SnSb}-\mathrm{C}$ and $\mathrm{SnSb}-\mathrm{TiC}-\mathrm{C}$ with different TiC and carbon contents before and after introducing 2 vol. \% of FEC additive into the electrolyte. 


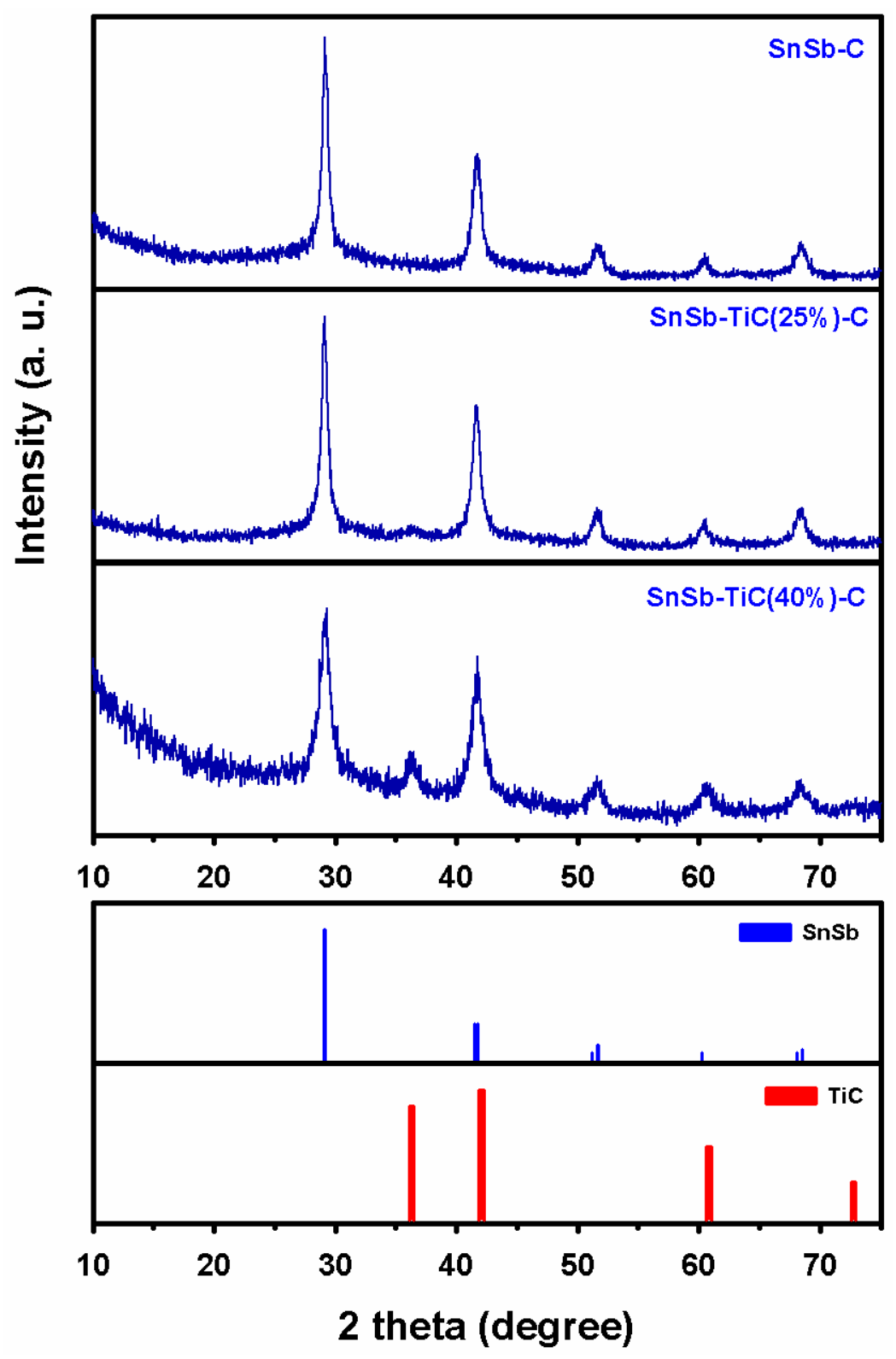

Fig. 1 

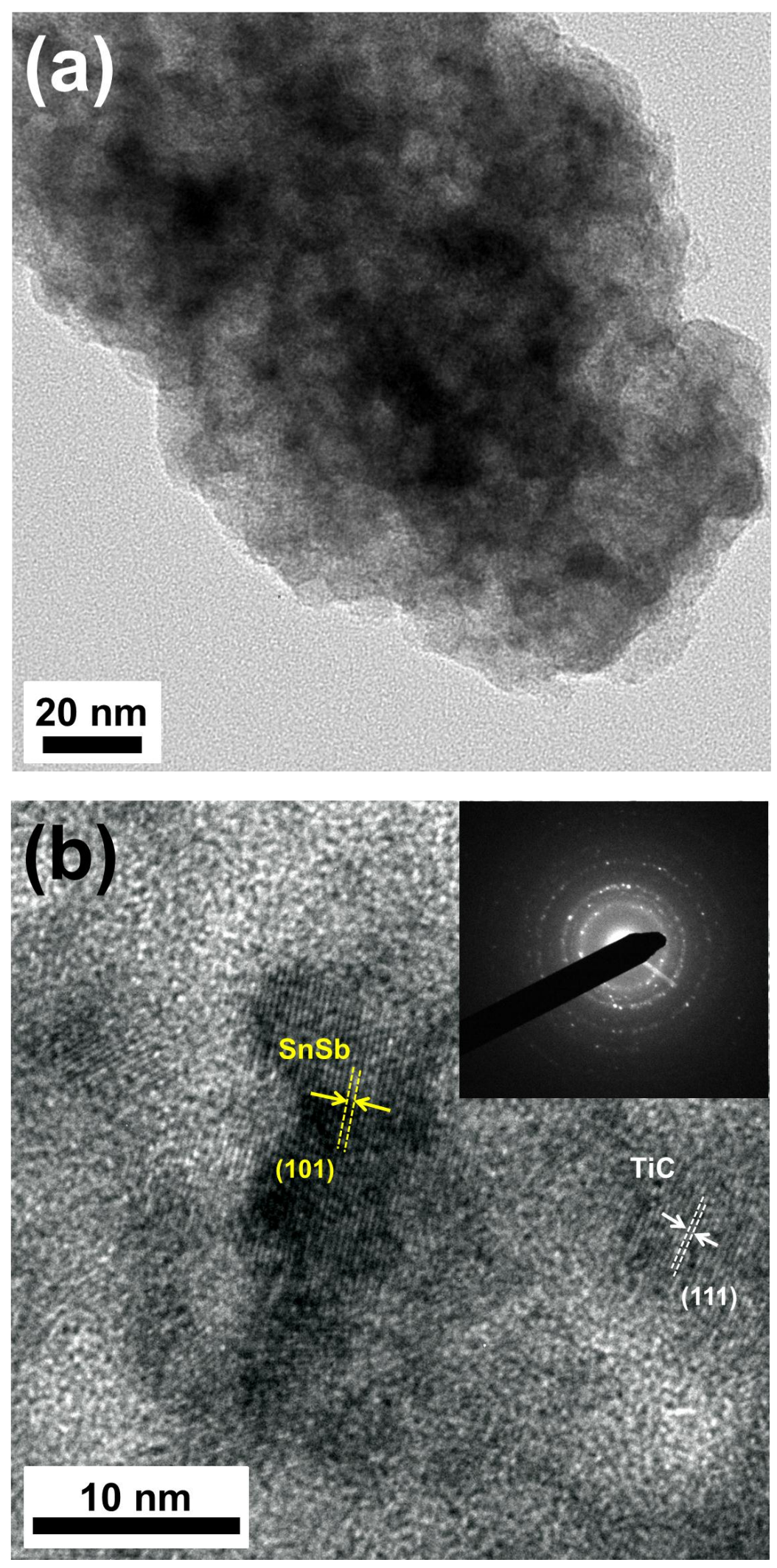

Fig. 2 


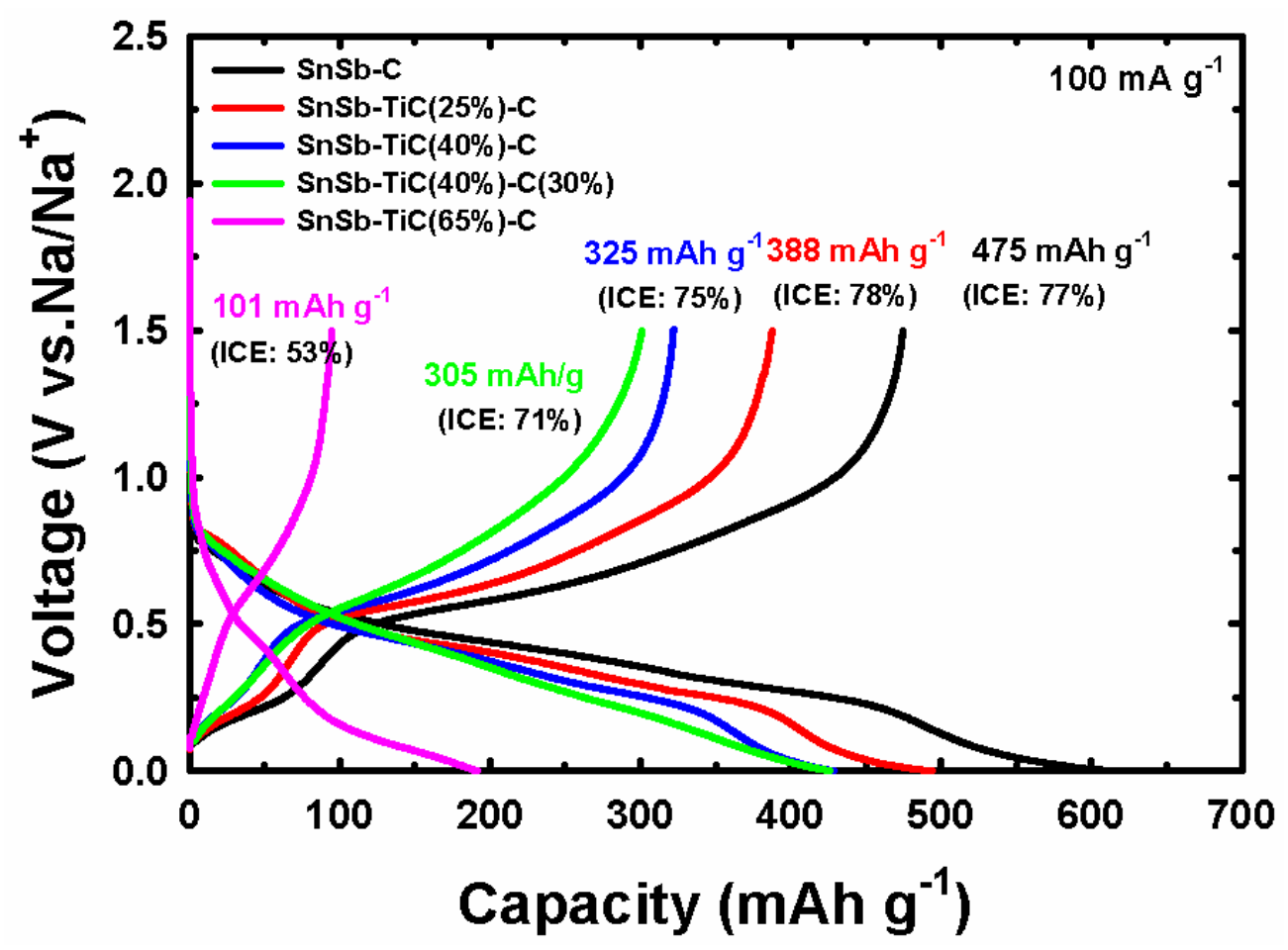

Fig. 3 

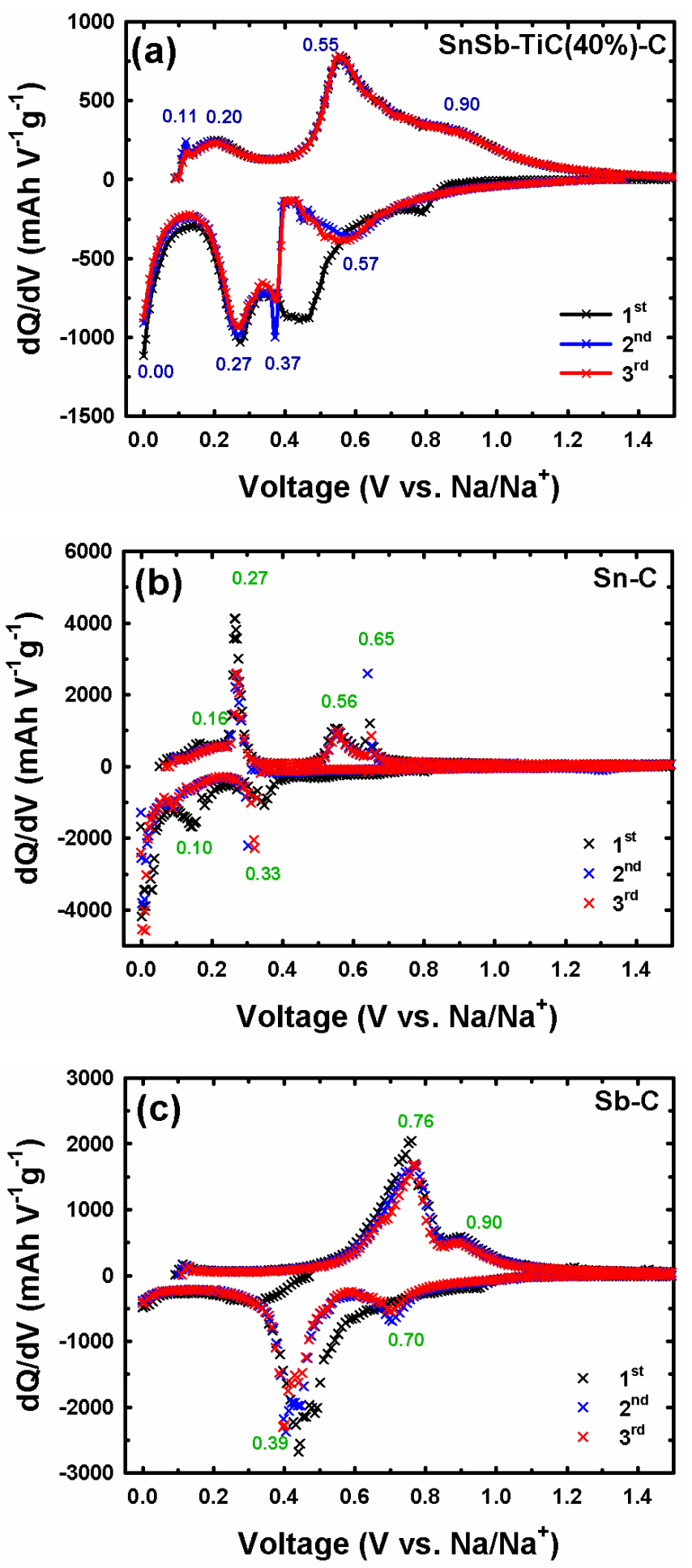

Fig. 4 


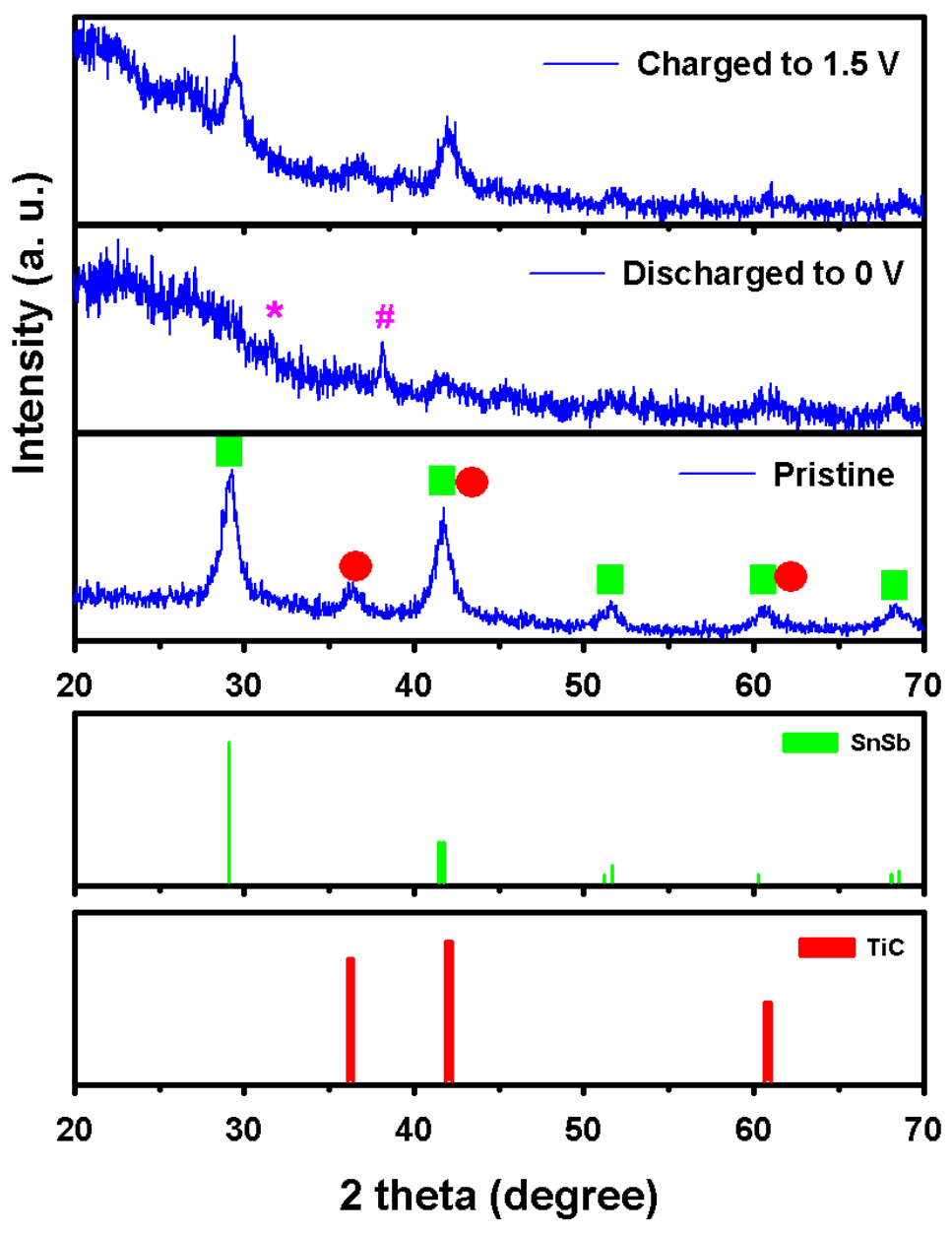

Fig. 5 

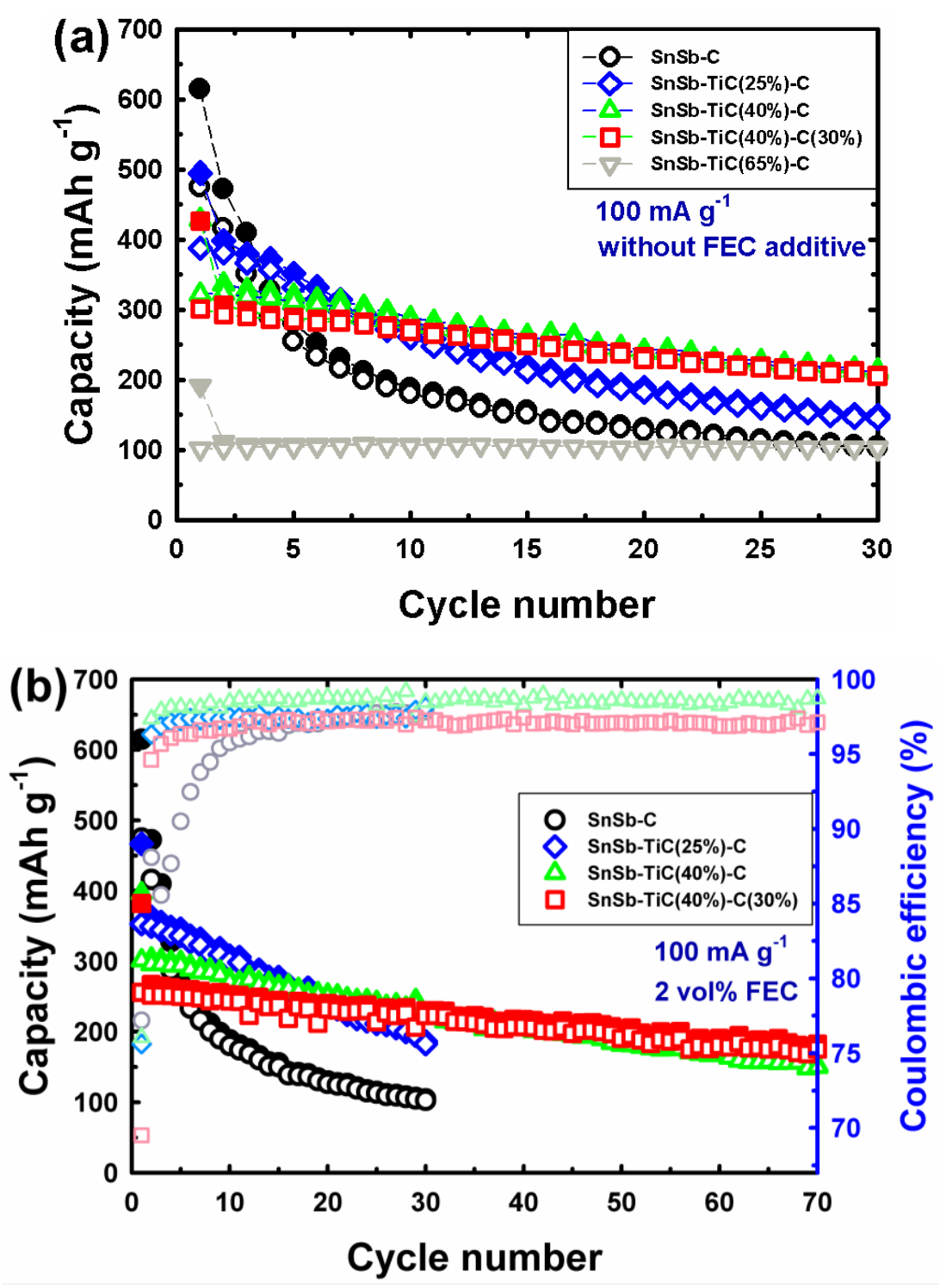

Fig. 6 

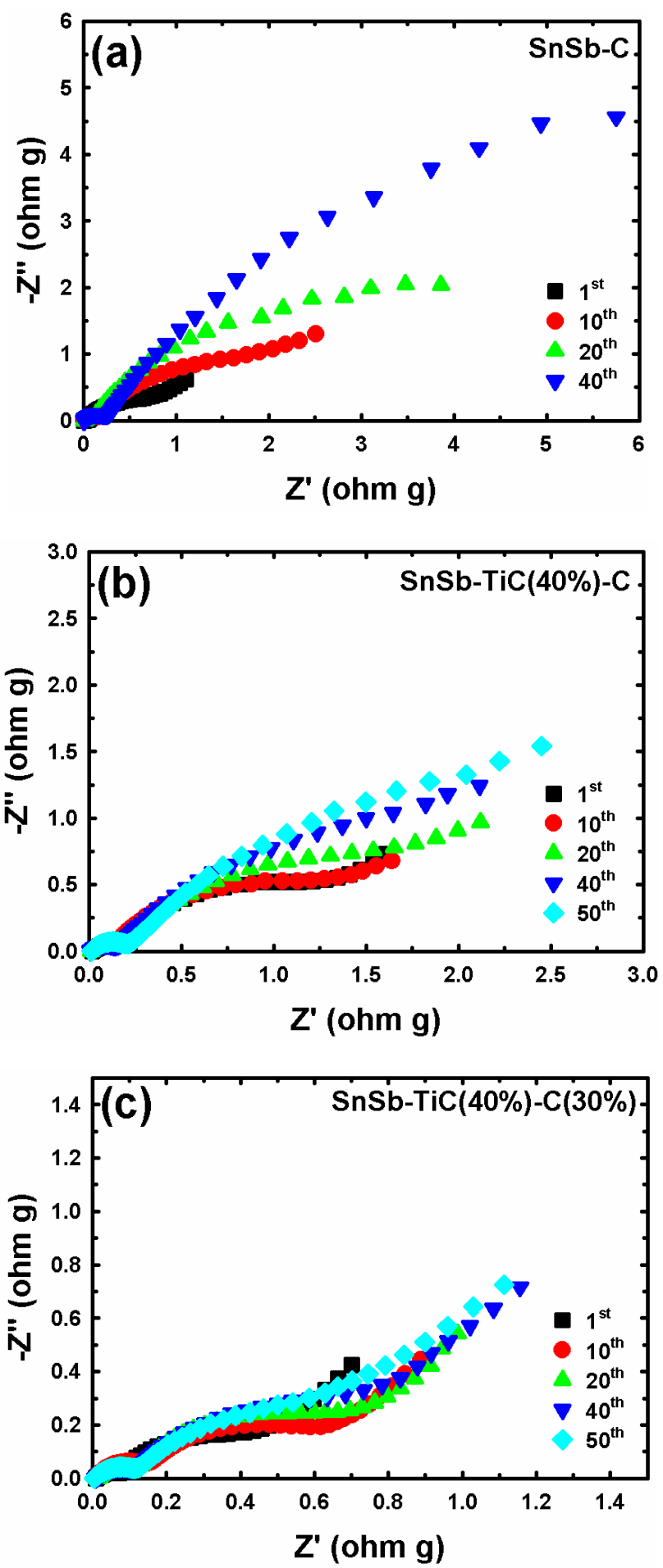

Fig. 7 

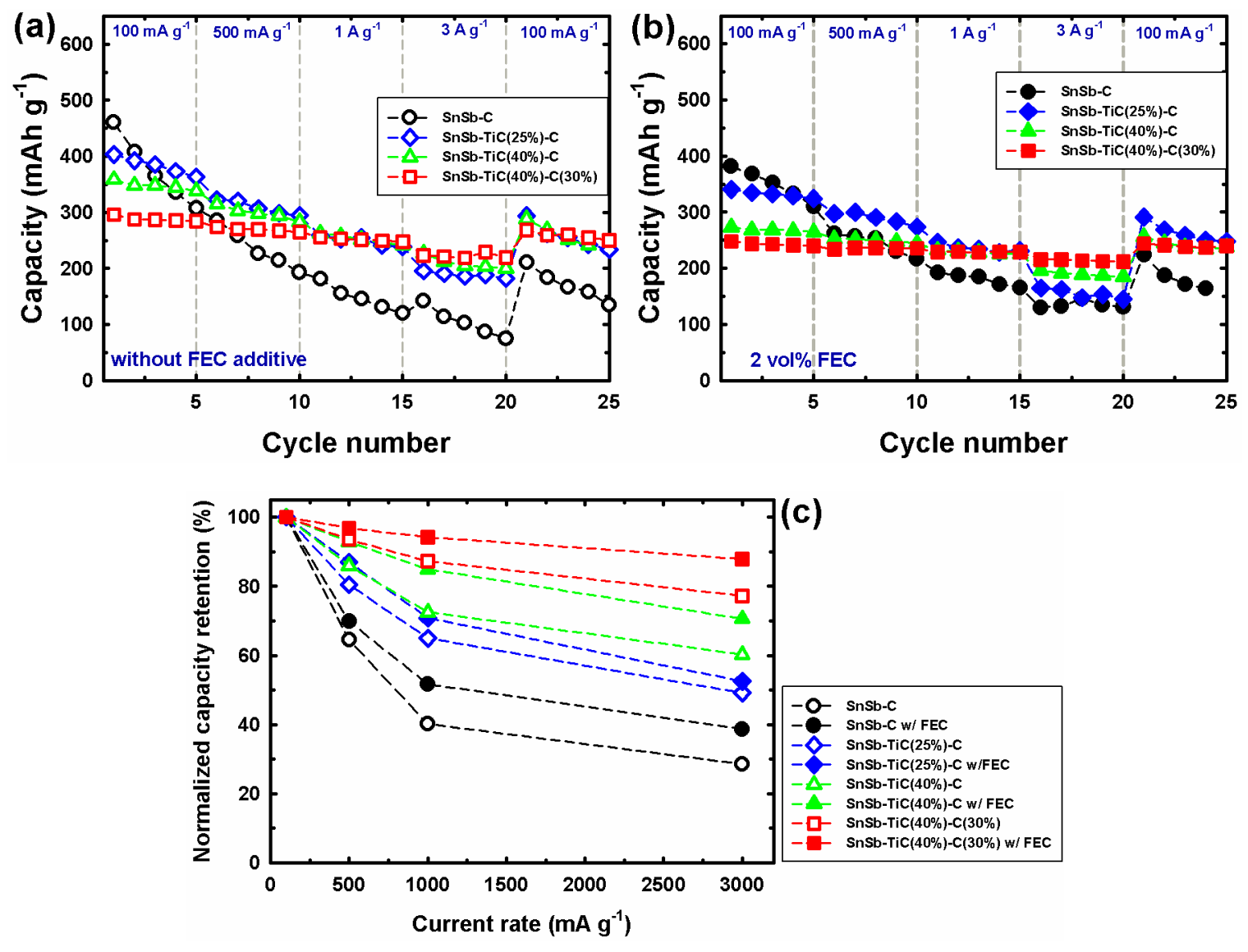

Fig. 8 


\section{Graphical Abstract}
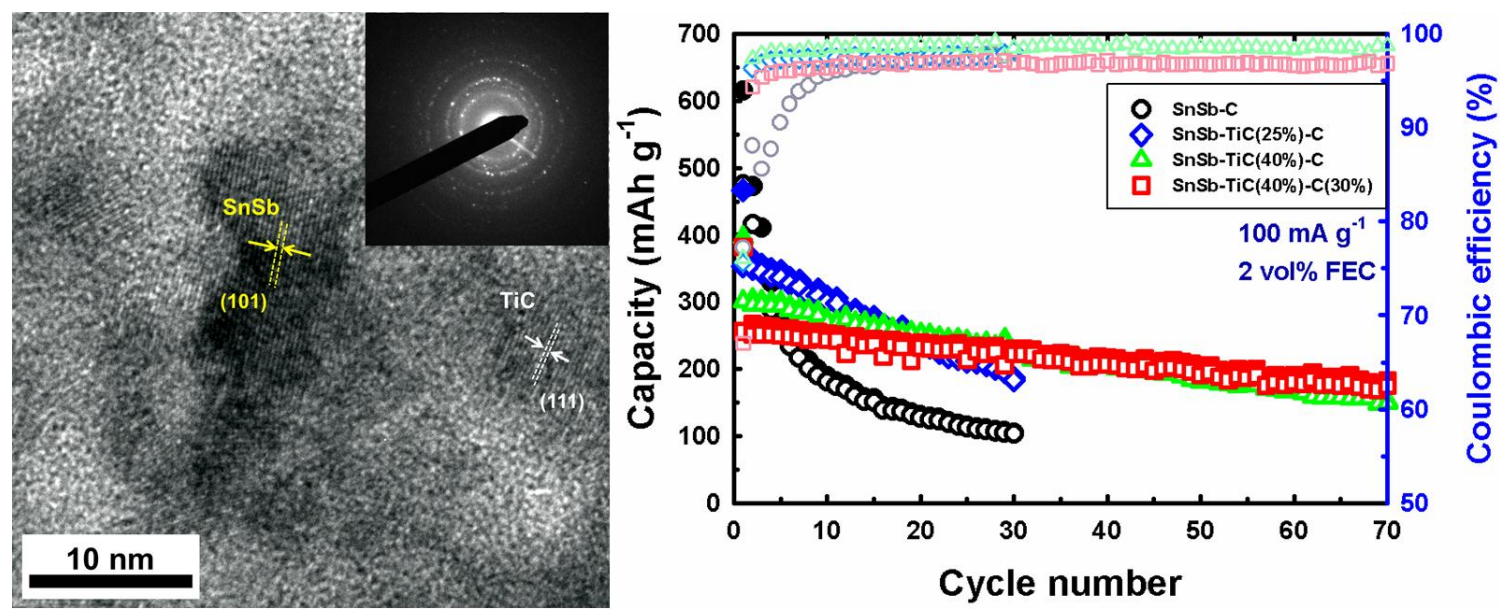